\title{
O VALOR DOS OVOS MORTOS COMO CRITÉRIO DE AVALIAÇÃO DA CURA PARASITOLÓGICA NA ESQUISTOSSOMOSE MANSONI*
}

\author{
José Roberto Lambertucci ${ }^{1}$, Emmanuel Pinto Dias ${ }^{2}$, Roberto Sena \\ Rocha $^{2}$, Enio Roberto Pietra Pedroso ${ }^{1}$ e Naftale Katz ${ }^{2}$
}

\begin{abstract}
Dezoito crianças com esquistossomose mansoni foram tratadas com a oxamniquine $(20 \mathrm{mg} / \mathrm{kg}$ de peso, dose única) e acompanhadas até o 22 ? mês pós-tratamento com 22 exames de fezes e uma biópsia retal no último mês. Dos 16 pacientes curados, cinco (31,3\%), não apresentaram qualquer tipo de ovo na biópsia retal, $11(68,7 \%)$, apresentaram ovos calcificados, oito (50\%), ovos "recém-mortos" $e$ três $(18,8 \%)$, granulomas. Para observar a dinâmica de desaparecimento de ovos dos tecidos, 31 camundongos, foram infectados com 100 cercárias de S. mansoni $e$ após 45 dias, tratados com drogas sabidamente esquistossomicidas. Os camundongos foram sacrificados 30,90,180, 260 e 400 dias após o tratamento. Observou-se diminuição progressiva dos ovos mortos nos fragmentos de intestino dos animais sacrificados, mas cerca de um ano após o tratamento os ovos hemitransparentes, calcificados, cascas e granulomas ainda foram encontrados. $O$ encontro apenas destes elementos, fala a favor da cura parasitológica.
\end{abstract}

Palavras chaves: Esquistossomose mansoni. Ovos mortos. Controle de cura. Tratamento. Biópsia retal.

A importância do encontro de ovos mortos de $S$. mansoni em fragmentos de tecidos retirados por biópsia retal, no controle de cura da esquistossomose, é ainda assunto controverso. Existe discordância, entre os poucos autores que estudaram o assunto, com relação ao tempo em que estes ovos são encontrados após o tratamento e qual o significado dos vários tipos de ovos mortos identificados.

Prata $^{8}$ realizando biópsia retal em grande número de pacientes até quatro meses após o tratamento, pôde observar o desaparecimento dos ovos mortos com miracidio retraído, sugerindo que $o$ encontro destes ovos a partir do 4 o mês levaria a pensar em infecção ativa. Propõe ainda sejam feitos estudos com período de tempo mais longo após o tratamento para estabelecer a real importância destes ovos no controle de cura da parasitose.

- Este trabalho foi realizado com auxílio do Conselho de Desenvolvimento Científico e Tecnológico (CNPq). Pedidos de Separatas: J. R. Lambertucci - Deptọ de Clínica Médica - Faculdade de Medicina da UFMG, 30.000 Belo Horizonte, Minas Gerais.

${ }^{1}$ Núcleo de Estudos sobre a esquistossomose (contribuição n! 22). Faculdade de Medicina da UFMG.

${ }^{2}$ Centro de Pesquisas René Rachou - FIOCRUZ.

Recebido para publicação em 13/04/83.
Cunha ${ }^{12}$ analisando sua experiência na realização de biópsias repetidas após o tratamento clínico, admite que o encontro de ovos chamados "recém-mortos" (hemitransparentes, granulosos, com embrião retraído, com estrutura apagada, granulações grosseiras, miracídio retraido e cascas transparentes), um ano após o tratamento seja indício de doença ativa.

Lambert ${ }^{4}$ e Silva ${ }^{9}$, em estudos no homem e em camundongos, demonstraram a presença de ovos mortos mais de um ano após o tratamento, mas estes autores só consideravam em suas observações os ovos calcificados.

O objetivo do presente trabalho é a identificação e classificação dos ovos mortos de $S$. mansoni na biópsia retal de crianças parasitadas e no intestino de camundongos, em diferentes periodos, após o tratamento e a cura parasitológica.

\section{MATERIAL E MÉTODOS}

Grupo humano - Quarenta e oito crianças com esquistossomose mansoni crônica, na faixa etária de seis a quatorze anos, foram tratadas com a oxamniquine oral $(20 \mathrm{mg} / \mathrm{kg}$ de peso, dose única) e avaliada a cura parasitológica através de 20 exames de fezes quantitativos (método Kato- 
$-\mathrm{Katz})^{3}$, tendo sido realizado dois exames por mês em dias consecutivos durante dez meses. Foram considerados curados os pacientes com exames de fezes persistentemente negativos a partir do primeiro mês pós-tratamento ${ }^{5}$. Dezoito destes pacientes considerados curados foram selecionados para o estudo, sendo que no $22{ }^{\circ}$ mês pós-tratamento, estes pacientes foram novamente submetidos a dois exames de fezes quantitativos (Kato-Katz) e uma biópsia retal (nove a quinze fragmentos) com oograma. Os ovos encontrados na biópsia retal foram classificados em "recém-mortos", calcificados e granulomas ${ }^{2}$. Seguindo a classificação de Cunha ${ }^{2}$, foram considerados ovos "recém-mortos": hemitransparentes, granulosos, com embrião retraído, com estrutura apagada, granulações grosseiras, miracídio retraído e cascas transparentes.

Grupo experimental - Trinta e um camundongos albinos (Mus musculus), fêmeas, com média de peso de 22 gramas, foram infectados com $100 \pm 20$ cercárias de $S$. mansoni da cepa LE por via transcutânea. Após 45 dias da infecção, os camundongos foram tratados com drogas sabidamente esquistossomicidas (oxamniquine, $100 \mathrm{mg} / \mathrm{kg}$ de peso, via oral; oltipraz, $125 \mathrm{mg} / \mathrm{kg}$, via oral; amoscanate, $100 \mathrm{mg} / \mathrm{kg}$, via oral; hycanthone, $80 \mathrm{mg} / \mathrm{kg}$, via intramuscular). A maioria dos camundongos foi tratada com associação destes medicamentos. Os animais foram sacrificados por fratura cervical, sendo: sete camundongos com 30 dias; sete com 90; oito com 180; seis com 260 e três com 400 dias após o tratamento.
$\mathrm{Na}$ ocasião do sacrifício, os animais foram perfundidos segundo o método de Pellegrino e Siqueir ${ }^{6}{ }$, com o objetivo de certificar-se da cura parasitológica. Após a perfusão dos camundongos parasitologicamente curados, foram retirados dez fragmentos de ileo, comprimidos entre lâmina e lamínula, examinados ao microscópio ótico com aumento de $250 \mathrm{X}$, contados todos os ovos encontrados e classificados segundo Pellegrino e cols. ${ }^{7}$.

Seis camundongos com as mesmas caracteristicas do primeiro grupo foram infectados da mesma forma, não tratados e sacrificados 45 dias após a infeç̧ão. Neste grupo controle seguiu-se a mesma metodologia na contagem e classificação de ovos do primeiro grupo.

\section{RESULTADOS}

Grupo humano - No 22 ' mês após o tratamento, 16 pacientes foram considerados curados (Tabela 1). Em cinco pacientes $(31,3 \%)$ a biópsia retal foi negativa para qualquer tipo de ovo (casos $7,8,10,11,12$ ). Nos outros 11 casos a distribuição do oograma foi: 11 pacientes com ovos calcificados $(68,7 \%)$, oito com ovos recém-mortos $(50 \%)$ e três com granulomas $(18,8 \%)$. Na Tabela 1 chama ainda a atenção dois pacientes não curados após o tratamento que apresentaram número significativamente maior de ovos recém-mortos do que os pacientes curados (casos 17 e 18).

Tabela 1 - Exame de fezes e biopsia retal com oograma no $22^{\circ}$ mês pós-tratamento em 18 crianças com esquistossomose mansoni, tratadas com oxamniquine.

\begin{tabular}{|c|c|c|c|c|c|}
\hline \multicolumn{2}{|c|}{ Exame de fezes } & \multicolumn{4}{|c|}{ Biopsia retal - oograma } \\
\hline Casos & (No ovos/grama) & ovos vivos & "Recém-mortos" & Calcificados & Granulomas \\
\hline 1 & 0 & 0 & 3 & 5 & 0 \\
\hline 2 & 0 & 0 & 1 & 1 & 0 \\
\hline 3 & 0 & 0 & 4 & 6 & 0 \\
\hline 4 & 0 & 0 & 2 & 6 & 4 \\
\hline 5 & 0 & 0 & 2 & 1 & 0 \\
\hline 6 & 0 & 0 & 0 & 1 & 0 \\
\hline 7 & 0 & 0 & 0 & 0 & 0 \\
\hline 8 & 0 & 0 & 0 & 0 & 0 \\
\hline 9 & 0 & 0 & 0 & 1 & 0 \\
\hline 10 & 0 & 0 & 0 & 0 & 0 \\
\hline 11 & 0 & 0 & 0 & 0 & 0 \\
\hline 12 & 0 & 0 & 0 & 0 & 0 \\
\hline 13 & 0 & 0 & 0 & 1 & 0 \\
\hline 14 & 0 & 0 & 12 & 4 & 6 \\
\hline 15 & 0 & 0 & 2 & 129 & $\begin{array}{l}0 \\
0\end{array}$ \\
\hline 16 & 0 & 0 & 1 & 111 & 2 \\
\hline 17 & 54 & 12 & 35 & 8 & 0 \\
\hline 18 & 12 & 6 & 28 & 33 & 0 \\
\hline
\end{tabular}


Lambertucci JR, Dias EP, Rocha RS, Pedroso ERP, Katz N. O valor dos ovos mortos como critério de avaliação da cura parasitológica na esquistossomose mansoni. Revista da Sociedade Brasileira de Medicina Tropical 16:158-161, Jul/Set, 1983

Grupo experimental - Acompanhando os resultados resumidos na Tabela 2, pode-se observar diminuição progressiva no percentual de ovos mortos encontrados em fragmentos de tecido no intestíno de camundongos. Duzentos e sessenta. dias após o tratamento, os ovos com embrião retraído já não foram mais encontrados, mas com 400 dias ainda se observaram os hemitransparentes $(2,7 \%)$ e cascas $(17,6 \%)$. Houve também participação percentual progressiva dos ovos calcificados.

Tabela 2 - Classificação e percentual dos ovos mortos encontrados no intestino de camundongos do grupo experimental, 30, 90,180, 260 e 400 dias após o tratamento e a cura parasitológica.

\begin{tabular}{|c|c|c|c|c|c|c|c|c|c|}
\hline \multirow{2}{*}{$\begin{array}{l}\text { Dias } \\
\text { após } \\
\text { o tra- } \\
\text { ta- } \\
\text { men- } \\
\text { to }\end{array}$} & \multirow{2}{*}{$\begin{array}{c}N o \mathrm{Ca}- \\
\text { mun- } \\
\text { don- } \\
\text { gos }\end{array}$} & \multirow{2}{*}{$\begin{array}{c}\text { Média do } \\
n \text { O de } \\
\text { ovos por } \\
\text { camun- } \\
\text { dongos }\end{array}$} & \multicolumn{5}{|c|}{ Ovos mortos } & \multicolumn{2}{|l|}{$(\%)$} \\
\hline & & & $\begin{array}{c}\text { Hemi- } \\
\text { trans- } \\
\text { parentes }\end{array}$ & Cascas & $\begin{array}{l}\text { Embrião } \\
\text { retraído }\end{array}$ & $\begin{array}{l}\text { Miraci- } \\
\text { dios re- } \\
\text { traidos }\end{array}$ & $\begin{array}{l}\text { Granulo- } \\
\text { sos }\end{array}$ & $\begin{array}{c}\text { Estrutura } \\
\text { apagada }\end{array}$ & $\begin{array}{l}\text { Calcifi- } \\
\text { cados }\end{array}$ \\
\hline 30 & 7 & 411 & 15,4 & 28,8 & 5,6 & 4,9 & 9,7 & 9,1 & 13,3 \\
\hline 90 & 7 & 178 & 14,5 & 31,5 & 2,8 & 8,9 & 12,3 & 3,7 & 14,7 \\
\hline 180 & 8 & 386 & 10,1 & 32,9 & 1,7 & 5,7 & 7,2 & 0,9 & 29,4 \\
\hline 260 & 6 & 494 & 4,5 & 44,4 & 0,0 & 10,5 & 1,5 & 0,1 & 28,9 \\
\hline 400 & 3 & 25 & 2,7 & 17,6 & 0,0 & 0,0 & 0,0 & 0,0 & 64,9 \\
\hline
\end{tabular}

Nos camundongos do grupo controle sacrificados 45 dias após a infecção e sem tratamento, foram encontrados em média 1.211 ovos vivos e 489 ovos mortos por camundongos. 0 percentual de ovos calcificados entre os ovos mortos foi de $4 \%$, bem menor do que nos camundongos tratados (Tabela 2). A distribuição percentual dos outros ovos mortos (hemitransparentes, cascas, embrião retraído, miracídios retraídos, granulosos, estrutura apagada), não diferiu da encontrada no grupo dos camundongos tratados até $\mathbf{3 0}$ dias após o tratamento.

\section{DISCUSSÃO}

A determinação do momento aproximado em que os ovos mortos desaparecem do intestino pode ajudar na definição da atividade parasitológica da doença, particularmente nos pacientes que eliminam pequeno número de ovos e em que o exame de fezes e a biópsia retal foram negativos para ovos viáveis.

Prata $^{8}$, por exemplo, afirma que os ovos com miracídio retraído são encontrados raramente quatro meses após o tratamento bem sucedido, tendo observado também diminuição extraordinária do número de cascas na mesma ocasião. $\mathrm{O}$ autor entretanto, não realizou biópsias após este pe- ríodo, não tendo sido possível estabelecer com segurança a época de desaparecimento destes ovos. Cunha $^{12}$ confirmou o desaparecimento precoce dos ovos com miracídio retraído após o tratamento e ampliou a observação para outros tipos de ovos que o autor chama de recém-mortos e, que segundo ele não seriam mais encontrados na biópsia retal realizada um ano após o tratamento, nos pacientes curados.

Com relação aos chamados ovos "recém-mortos", nossos dados não coincidem com observações anteriores. De fato, pode-se concluir que: 1) os ovos mortos com embrião retraído são os primeiros a desaparecer do in testino (entre 180 e 260 dias); 2) os ovos granulosos, cs ovos com miracídio retraído e com estrutura apagada, desaparecem depois do nono mês após o tratamento. Por outro lado, as cascas e os ovos hemitransparentes ainda foram encontrados no intestino de camundongos até 400 dias e os ovos hemitransparentes até o 22 ? mês nas crianças biopsiadas. $\mathrm{O}$ encontro de cascas no intestino de camundongos, até 52 semanas após o tratamento bem sucedido faz também parte das observações de Lambert ${ }^{4}$.

Não encontramos na literatura consultada definição adequada do termo "ovos recém-mortos”. Já que alguns destes ovos foram encontrados 
Lambertucci JR, Dias EP, Rocha RS, Pedroso ERP, Katz N. O valor dos ovos mortos como critério de avaliação da cura parasitológica na esquistossomose mansoni. Revista da Sociedade Brasileira de Medicina Tropical 16:158-161, Jul/Set, 1983

mais de um ano após o tratamento bem sucedido (por exemplo, as cascas e os ovos hemitransparentes), talvez fosse melhor identificá-los apenas como ovos mortos.

Com relação aos ovos calcificados, Prata $^{8}$ é de opinião que após dois anos do tratamento, a maioria das biópsias já se negativou para todos os tipos de ovos, raramente observando-se ovos calcificados. Silva ${ }^{9}$, entretanto, relata em dois pacientes a presença de ovos mortos calcificados dois anos após o tratamento e a cura parasitológica. Apesar de não existir trabalho definitivo sobre este. assunto, a maioria dos autores concorda que os ovos calcificados e os granulomas são de desaparecimento mais demorado. Onze pacientes $(68,7 \%)$, dos 16 curados na nossa casuística, ainda apresentavam ovos calcificados no 22 \% mês pós-tratamento, sendo dois casos com grande número (casos 15 e 16).

Em resumo, pode-se dizer que até seis meses após o tratamento bem sucedido, praticamente todos os tipos de ovos mortos podem ser encontrados. Já a partir de um ano existe uma diminuição marcante no número de ovos mortos, e inclusive alguns tipos de ovos não mais são encontrados. Todavia, as cascas, os ovos mortos hemitransparentes, os calcificados e granulomas foram vistos até o 400 \% dia pós-tratamento em camundongos e, 22 ? mês nas crianças tratadas e curadas. $O$ encontro apenas destes elementos, fala a favor da cura da parasitose.

\section{SUMMARY}

Eighteen children with schistosomiasis mansoni were treated with oxamniquine $(20 \mathrm{mg} / \mathrm{kg}$ body weight, single oral dose) and follow-up was continued for twenty two months post-treatment, with twenty two stool examinations and one rectal biopsy in the last month. From 16 children considered as cured, the results of the oogram in the rectal snips revealed in 5 (31.3\%), no eggs; in 11 $(68.7 \%)$, calcified eggs; in $8(50 \%)$, "recent-dead" eggs and in 3 (18.8\%), granulomas. To study the dynamics of disappearance of S. mansoni eggs in the tissues, 31 white mices were infected with $100 \mathrm{~S}$. mansoni cercariae and after 45 days treated with an association of known schistosomicidal drugs. The animals were sacrificed 30, 90, 180, 260 and 400 days after treatment and ileal fragments were microscopically examined and oograms were performed. A significant decrease in the number of dead eggs was observed, and after one year. post-treatment only semi transparents, shells and calcified eggs as well as granulomas were still found. The finding of those types of eggs alone is a strong evidence of parasitological cure.

Key words: Schistosomiasis mansóni. Dead eggs. Cure control. Treatment. Rectal biopsy.

\section{AGRADECIMENTOS}

Os autores agradecem ao Prof. Aloísio Sales da Cunha pela realização das biópsias retais e aos Srs. Gercy de Souza Morais e Antônio Emídio Ferreira pelo auxílio técnico.

\section{REFERẼNCIAS BIBLIOGRĀFICAS}

1. Cunha AS. Avaliação da terapêutica da esquistossomose mansoni pelo oograma; observação sobre a ação do gluconato de sódio e antimonilo. Tese de Doutorado, Universidade Federal de Minas Gerais, Minas Gerais, 1961.

2. Cunha AS, Cançado JR. Tratamento clínico. In: Cunha AS (ed) Esquistossomose mansoni, 1ạ edição. Editora da USP, São Paulo, p 327-382, 1970.

3. Katz N, Chaves A, Pellegrino J. A simple device for quantitative stool thick-smear technique in schistosomiasis mansoni. Revista do Instituto de Medicina Tropical de São Paulo 14:397-402, 1972.

4. Lambert CR. The significance of black eggs in schistosomiasis. Annals of the New York Academy of Sciences 160: 486-490, 1969.

5. Lambertucci JR. Ensaio terapêutico com a oxamniquine oral na esquistossomose mansoni crônica. Tese de Mestrado, Universidade Federal de Minas Gerais, Minas Gerais, 1981.

6. Pellegrino J, Siqueira AF. Técnica de perfusão para colheita de $S$. mansoni em cobaias experimentalmente infectadas. Revista Brasileira de Malariologia e Doenças Tropicais, 8: 589-597, 1956.

7. Pellegrino J, Oliveira CA, Faria J, Cunha AS. New approach to the screening of drugs in experimental schistosomiasis mansoni in mice. American Journal of Tropical Medicine and Hygiene, 11:201-215, 1962.

8. Prata A. Biópsia retal na esquistossomose mansoni; bases e aplicações no diagnóstico e tratamento. Tese de Catedrático, Serviço Nacional de Educação Sanitária, Rio de Janeiro, 1957.

9. Silva R. Discussion. Acta Tropica 9 (Suppl.): 259, 1966. 